\title{
Crónica comunitaria: la actualidad institucional y económica de España en el marco de la Union Europea
}

\author{
Beatriz Iñarritu Ibarreche \\ Profesora de la Universidad Comercial de Deusto
}

\begin{abstract}
Sumario: I. Introducción. - II. El Estado de la Integración. II.1. La crisis de la eurozona: rescate a Chipre, nuevos recortes en Portugal y visita de la troika a España. II.2. Gobernanza económica: semestre europeo y mecanismo de alerta de desequilibrios macroeconómicos: informes sobre la economía española. II.3. Sentencia del tribunal de la AELC: Islandia no deberá indemnizar a Holanda y Reino Unido. II.4. Reino Unido: debate sobre la permanencia en la Unión Europea. - III. La Actualidad Institucional de la Unión Europea. III.1. Consejos Europeos y Cumbres del Euro. III.2. Eurogrupo: relevo en la presidencia. - IV. Cuestiones generales de la actualidad económica. IV.1. BCE: Nueva rebaja de los tipos de interés. IV.2. Gobernanza económica: paquete legislativo sobre supervisión presupuestaria («two-pack»). IV.3. Tribunal de Justicia: Sentencia sobre la ley hipotecaria española. IV.4. Política de competencia: nueva multa a Microsoft. IV.5. Banca: nueva norma sobre la remuneración de los directivos y avances en la unión bancaria.
\end{abstract}

\section{Introduccion}

En el primer semestre de 2013 Chipre se ha convertido en un nuevo país de la Eurozona que ha debido ser rescatado. Tras una primera propuesta de imponer una tasa a todos los ahorradores del país, la UE debió rectificar y plantear una penalización para los depósitos superiores a 100.000 euros. La confusión se acrecentó con las declaraciones contradictorias de las instituciones comunitarias sobre si este modelo, en el que se repercute parte del coste a los acreedores de las entidades financieras, podría repetirse. Y sin duda que el debate británico sobre su permanencia en la UE añadió una dosis extra de desgaste de imagen de la Unión.

También destacó el giro de la Comisión hacia una mayor permisividad en la consecución del objetivo del Déficit (2016 para España), a pesar de que la exigencia de políticas de austeridad parece no cuestionarse. Las opiniones críticas, como la expresada por Juncker en su despedida de la presidencia del Eurogrupo, no parecen tener efecto alguno en las orientaciones de política económica de la Eurozona. 
In the first semester 2013 Cyprus became a new member State of the Eurozone to be rescued. After a first proposal to impose a tax to all the savers in the country, the EU had to rectify and propose a penalization just to those deposits over 100.000 euro. Confusion increased with contradictory statements coming from the Community institutions referring to the possibility that this model, in which part of the cost is supported by the creditors of the banking entities, could be repeated. And, undoubtedly, the British debate about its permanency in the EU added an extra dose of weakness for the Union's image.

It was also remarkable the Commission's change towards an increased permissiveness in the achievement of the objective of the Deficit (2016 for Spain), although the requirement of austerity policies seems not to be questioned. Critical opinions, like that expressed by Juncker at his farewell speech as president of the Eurogroup, do not seem to have any effect in the guidance of economical policy within the Eurozone.

\section{El estado de la integración}

\section{II.1. La crisis de la eurozona: rescate a Chipre, nuevos recortes en Portugal y visita de la troika a España}

Chipre se convirtió, en el primer semestre de 2013, en el nuevo país «rescatado» de la Eurozona.

El 25 de marzo, y tras una dura negociación, la «troika», los países de la Eurozona y Chipre alcanzaron un acuerdo para salvar al país mediterráneo de la bancarrota y a la Unión Monetaria de una crisis sin precedentes.

Nicosia se comprometía a reestructurar su mayor entidad financiera y a cerrar el segundo banco del país. Asimismo, prometía imponer severas quitas a los accionistas, acreedores y depositantes con más de 100.000 euros en su cuenta. Se imponía también un régimen de limitación a la circulación de capitales, con limitaciones a la salida de dinero del país. Los bancos chipriotas cerraron sus puertas durante más de diez días.

La Eurozona daba marcha atrás puesto que, previamente, se había alcanzado un acuerdo en el que se establecía un impuesto para todos los depósitos, incluidos los inferiores a 100.000 euros, lo que vulneraba las disposiciones de un Reglamento comunitario de 2008 que establece la garantía de los «pequeños» depósitos (en el primer acuerdo se proponía una tasa superior al 6\% para estos pequeños ahorradores). El rechazo del Parlamento chipriota a este primer acuerdo así como las protestas de los ciudadanos fueron clave en la renegociación.

Chipre se convertía, así todo, en «un experimento», puesto que se convertía en el primer caso de rescate de la Eurozona en el que los ahorradores 
han debido pagar por él. El plan de rescate contemplaba, asimismo, duras medidas de recortes, reformas y privatizaciones, encaminadas al regreso de Chipre a lo que Bruselas denomina la senda del «crecimiento sostenible».

La polémica también se escenificó entre las instituciones, ya que mientras el vicepresidente de la Comisión, Olli Rehn, sostenía que «el caso de Chipre es único y excepcional», el presidente del Eurogrupo, Jeroen Dijsselbloem, insinuaba que el modelo chipriota podría servir de «modelo» para futuros rescates, lo que desató las alarmas en los mercados financieros con bajadas generalizadas en las Bolsas europeas.

El 3 de abril se cerraba el preacuerdo entre la Troika y Nicosia, que significaba el rescate a Chipre por un valor de 10.000 millones de euros (el Fondo Monetario Internacional aportaría el 10\%), a un plazo de 22 años y con un tipo de interés entre 2,5 y 2,7\%. Los responsables de la Comisión Europea y del FMI enviaron un mensaje de apoyo al país, señalando su intención de «contribuir a que Chipre recupere la estabilidad financiera, la sostenibilidad de las finanzas públicas y el crecimiento».

En el análisis de las causas de la crisis chipriota se destaca, en efecto, la sobredimensión del sector financiero (el sector bancario supone el $550 \%$ del PIB del país) y el fuerte impacto de la quita pactada sobre la Deuda griega.

También en abril el gobierno portugués anunció un nuevo plan de recortes en Sanidad, Educación y prestaciones de Seguridad Social. El primer ministro, Passos Coelho, justificó la decisión en que el país se encontraba en un estado de «emergencia nacional» para poder cumplir con los compromisos adquiridos con la Troika.

«Tenemos que evitar un nuevo rescate», señaló Coelho en una solemne alocución televisada que siguió a una reunión extraordinaria del Consejo de ministros y al fallo del Tribunal Constitucional que invalidaba un paquete de medidas por valor de 1.350 millones de euros y que afectaban a las pagas extraordinarias de los funcionarios y pensionistas, así como a las prestaciones por desempleo y bajas por enfermedad.

Por su parte, la Troika realizó una nueva inspección al rescate de la banca española entre los días 21 y el 31 de mayo. Tras su estancia en Madrid, sus miembros, representantes de la Comisión Europea, Banco Central Europeo y Fondo Monetario Internacional, emitieron sendos comunicados con un primer balance de conclusiones, en los que se constataba que el programa «va por el buen camino», porque la reestructuración del sector financiero español avanza al ritmo adecuado y porque ya se han cumplido casi todas las condiciones impuestas en el Memorándum de Entendimiento que se pactó en 2012 para recibir un préstamo de hasta 100.000 millones de euros para la banca.

Pero tanto la Comisión y el BCE en su comunicado conjunto, como el FMI en el suyo, advertían sobre la fragilidad del sector financiero español 
como consecuencia de la grave crisis económica que sufre el país. Y pedían que se mantenga una «estrecha vigilancia» para comprobar el impacto del deterioro económico en la calidad del balance de las entidades financieras, sobre todo, añadían la Comisión y el BCE, «ahora que el fin del programa se acerca».

En efecto, la línea de crédito abierta para España por el Mecanismo Europeo de Estabilidad (MEDE) de 100.000 millones de euros expira el próximo 31 de diciembre. Hasta esa fecha, el Gobierno podría solicitar un nuevo desembolso tras los 40.000 millones recibidos para la recapitalización, entre otros, de Bankia, Novagalicia, Catalunya Bank y Banco de Valencia.

Con un mensaje lleno de advertencias, la Troika alertaba, por tanto, de que los activos bancarios en España continúan deteriorándose, lo que podría provocar que, finalmente, los bancos con problemas necesiten más ayudas europeas. El Gobierno español, por su parte, ha asegurado que no pedirá más dinero, aunque cada día surgen más voces que reclaman una nueva inyección a la banca para que regrese el crédito.

\section{II.2. Gobernanza económica: Semestre europeo y mecanismo de alerta de desequilibrios macroeconómicos: informes sobre la economía española}

En noviembre de 2012 se iniciaba un nuevo ciclo, para 2013, del «Semestre Europeo» y del «Procedimiento de Desequilibrios Macroeconómicos». El Semestre comenzaba con la publicación la «Encuesta Anual sobre el Crecimiento 2013 y el Procedimiento de Desequilibrios» se iniciaba con la publicación del «Informe del Mecanismo de Alerta 2013» que reclamaba la realización de «Exámenes Exhaustivos» para catorce Estados miembros de la UE, incluida España.

De esta manera, y siguiendo las secuencias previstas en ambas iniciativas, a lo largo del primer semestre de 2013 se han publicado diferentes informes sobre la evolución de la Economía europea.

Los primeros fueron los denominados «Exámenes Exhaustivos» solicitados en virtud del Procedimiento de Desequilibrios Macroeconómicos, informes realizados por la Comisión sobre catorce países y que hizo públicos el 10 de abril.

Bruselas señaló entonces que España era, junto con Eslovenia (considerado firme candidato a pedir un rescate por los riesgos «sustanciales» de su sector financiero), uno de los países con desequilibrios económicos más graves de la Unión. A pesar de que la Comisión se mostraba razonablemente satisfecha con los esfuerzos de austeridad realizados en España, también hizo valer su descontento con el ritmo de avance de las reformas em- 
prendidas. En palabras del comisario de Economía, Olli Rehn, «aunque se han adoptado medidas, la agenda reformista está incompleta, e incluso reformas ya adoptadas no han mostrado todos sus efectos por los retrasos en su activación. Como resultado, la capacidad de ajuste de la Economía sigue siendo insatisfactoria, y lo peor recae en el empleo».

Las recomendaciones del ejecutivo comunitario cubrían un amplio espectro de medidas, que debían contemplarse en los Programas de Estabilidad y de Reforma españoles (programas que debían ser presentados por el gobierno español a la Comisión el 26 de abril): un nuevo incremento de impuestos, nuevos ajustes en las pensiones y en la reforma laboral, y nuevas medidas para atajar el multimillonario déficit energético.

En el ámbito laboral, Bruselas pedía abaratar el despido improcedente y reclamaba un impulso en las políticas activas de empleo. En el campo de las pensiones, su recomendación es avanzar hacia la desvinculación de las pensiones a la inflación y la introducción de factores de corrección que incluyan la evolución del PIB y el número de cotizantes y pensionistas. Por lo que se refiere a la fiscalidad, la Comisión planteaba la reducción del número de productos con tipos reducidos de IVA, o elevar dichos tipos.

La justificación de esta nueva «vuelta de tuerca» se basaba en el cuadro macroeconómico de España. Según Bruselas, la Economía española no volverá a crecer hasta 2014, el paro superará el $27 \%$ en 2013, y la Deuda pública alcanzará el 100\% del PIB en 2015.

Siguiendo los pasos previstos en el «Semestre Europeo», el 26 de abril el Consejo de ministros español aprobó el «Programa Nacional de Reformas» y la actualización del «Plan de Estabilidad 2013-2016», documentos que, a continuación, el gobierno debía remitir a la Comisión europea.

Estos Programas contemplaban, como medidas relevantes, la prórroga en 2014 de la subida del Impuesto sobre la Renta IRPF (a pesar de que en su día el gobierno español había señalado que esta subida sería temporal y su vigencia se limitaría a 2012 y 2013), así como el aumento del Impuesto de Sociedades (mediante la supresión de determinadas deducciones) y de los Impuestos Especiales. También incluían la futura aprobación de una ley de desindexación de algunos precios públicos a la inflación.

En el Plan de Estabilidad, el ejecutivo presentaba un nuevo cuadro macroeconómico en el que aplazaba la consecución del objetivo del Déficit al 3\% del PIB hasta 2016, y la vuelta al crecimiento hasta 2014 (incremento del 0,5\% del PIB). El gobierno planteaba una corrección pesimista de sus anteriores previsiones, ya que modificaba la previsión de variación del PIB del $-0,5 \%$ al $-1,3 \%$ para este año.

Apenas un mes después, el 29 de mayo, la Comisión presentaba su valoración de los Programas Nacionales de Reforma, y de los Planes de Estabilidad y Convergencia de los Estados miembros, así como sus re- 
comendaciones anuales a los Estados miembros, recomendaciones que, posteriormente, debían debatirse y aprobarse formalmente en el Consejo Europeo de finales de junio.

En palabras del presidente de la Comisión, José Manuel Durao Barroso, «es preciso liquidar los dos legados duraderos de esta crisis, la grave pérdida de competitividad de muchos Estados y el desempleo persistente, con todas sus consecuencias sociales».

Muchos analistas concluyeron que, sus recomendaciones, Bruselas admitía una cierta relajación respecto a la disciplina de la austeridad, al conceder más tiempo a seis Estados, incluida España, para cumplir los compromisos de reducción del Déficit público.

En el caso español, Bruselas consideraba que, en efecto, nuestro país cumplía las condiciones para ampliar en dos años el plazo para poner fin a la situación de Déficit excesivo que está lastrando la economía. Con esta decisión, España deberá conseguir que en 2016 su Déficit público global sea inferior al 3\% del PIB, siendo los objetivos previos del 6,5\% en 2013, el 5,8\% en 2014, el 4,2\% en 2015, y finalmente el 2,8\% en 2016.

Esta nueva senda de objetivos del Déficit significa, sin duda, una «liberación» en la presión de cara a afrontar de manera inmediata nuevos severos recortes. Sin embargo, a cambio de este retraso, Bruselas planteó la necesidad de una aceleración en la reforma de las pensiones, una profundización en la reforma laboral y la aprobación de subidas del IVA y de los impuestos sobre los carburantes.

La evaluación del Programa español de Reformas concluía, en este sentido, que, aunque la dirección es correcta, «es urgente aprobar y aplicar con eficacia las reformas pendientes siguiendo un cronograma». En este calendario de recomendaciones, Bruselas incidía, en especial, en las pensiones, en el mercado de trabajo y en los impuestos:

- Pensiones: Bruselas solicitaba a España la culminación de la regulación del «factor de sostenibilidad», mecanismo que está siendo diseñado por un grupo de expertos para preservar la estabilidad financiera del sistema de pensiones y que podría conllevar rebajas en las pensiones y nuevos aumentos de la edad de jubilación. La Comisión proponía explícitamente que «la edad de jubilación vaya aumentando en función del aumento de la esperanza de vida». Esta reforma se aplicaría ya desde 2014.

- Empleo: Bruselas pedía una evaluación urgente de la reforma laboral y que se regulen cambios, $\mathrm{y}$ «si es necesario» antes de septiembre de este año.

- Impuestos: España debería realizar una «revisión del sistema tributario» antes de marzo de 2014. La Comisión Europea apuesta por li- 
mitar el uso de los tipos reducidos del IVA y por incrementar los tributos medioambientales, «sobre todo» los impuestos que se aplican sobre los carburantes.

El aparente giro de la Comisión, más proclive al impuso del crecimiento y a reconocer los efectos secundarios de la austeridad a ultranza, parecía plasmarse en la decisión del Ejecutivo comunitario de no abrir un procedimiento sancionador contra España, candidata a ello por sus «graves desequilibrios macroeconómicos». El Gobierno español evitaba un procedimiento que habría conllevado una vigilancia reforzada - casi una intervención - de la política económica nacional y el riesgo de multas de gran cuantía. Bruselas decidía «abrir la mano con el Déficit», y aunque esta decisión no suponía el fin de los recortes, sí los aligeraba.

\section{II.3. Sentencia del tribunal de la AELC: Islandia no deberá indemnizar a Holanda y Reino Unido}

El Tribunal de la Asociación Europea de Libre Comercio (AELC) emitió a finales de enero un dictamen en el que apoyaba a Islandia en su negativa a cubrir las pérdidas de clientes británicos y holandeses por sus depósitos en el banco Icesave, filial «on line» del Landsbanki, segundo banco del país en 2008 y que fue nacionalizado entonces por el gobierno islandés, al igual que los principales institutos crediticios de Islandia tras la quiebra del sector bancario en octubre de dicho año.

Islandia, al contrario de países como España o Irlanda, decidió que los contribuyentes islandeses no debían costear los desmanes del sector financiero y que tampoco debían compensar a los británicos y holandeses que perdieron sus ahorros en bancos del país. Los ciudadanos islandeses rechazaron en dos ocasiones, a través de sendos referendos, dicha compensación, y cinco años después del hundimiento del sistema bancario islandés, el Tribunal europeo dio la razón a Reikiavik en su negativa a compensar a británicos y holandeses por la quiebra del Icesave.

El Tribunal de la AELC sentenció que el país no violó la ley cuando se negó a devolver a 300.000 ahorradores extranjeros el dinero depositado en unas entidades que ofrecían unos intereses que entonces parecían irrechazables. Según el Tribunal, Islandia no estaba obligada a pagar a estos ahorradores extranjeros, ya que «el fondo de garantía de depósitos fue incapaz de hacer frente a sus obligaciones en el caso de una crisis sistémica». De esta manera, la Corte sentaba un precedente para otras posibles situaciones límite en que los Estados no pudieran devolver el dinero de sus ahorradores extranjeros. 
Un portavoz comunitario se apresuró a afirmar que las obligaciones de los fondos de garantía de depósitos se mantienen «vigentes también si hay una crisis sistémica», y que la Comisión Europea necesitaría un tiempo para estudiar el fallo. Sin embargo, otros expertos señalaron que la sentencia debía ser del agrado de los Estados, incluidos Holanda y Reino Unido, puesto que gracias a ella los países podrán dejar de ser responsables sobre todos los depósitos bancarios.

Tras la bancarrota del banco islandés, los Gobiernos británico y holandés usaron sus arcas para compensar a los clientes nacionales del dicho banco, y poco después iniciaron el proceso legal que, por fin, llegó a su fin en Enero, ya que la sentencia no admite recurso.

\section{II.4. Reino Unido: Debate sobre la permanencia en la Unión Europea}

El primer ministro británico, David Cameron, anunció el 14 de mayo un borrador de proposición de ley que sienta las bases de una eventual consulta sobre la permanencia del Reino Unido en la Unión Europea. Esbozaba un plan para convocar antes del 31 de diciembre de 2017 un plebiscito en el que se requeriría a los electores a responder con un «sí» o un «no» a la pregunta «¿Cree que el Reino Unido debería continuar siendo miembro de la UE?».

Sin embargo, un sector de los diputados conservadores del partido del primer ministro consideró insuficiente la iniciativa y presentó una enmienda en el Parlamento británico. Sin embargo, la Cámara de los Comunes la rechazó por 277 votos frente a 130. Diversos parlamentarios del ala euroescéptica de los conservadores, cuya postura ha ganado peso tras el auge electoral del partido antieuropeo UKIP en las elecciones locales celebradas a principios de mayo, sostuvieron que su voto sería, a día de hoy, contrario a seguir perteneciendo a la UE.

La iniciativa británica pretendería negociar las condiciones de su pertenencia y mejorar su «contrato» con Europa. La amenaza de convocar un referéndum sobre su salida ya es interpretada como un «chantaje continuo» que, si bien antes asustaba, ahora parece provocar cierto hartazgo en las instituciones comunitarias.

Cameron ya había informado sobre sus planes en enero, cuando anunció que, si gana las elecciones en 2015, propondrá un cambio en los Tratados. Su intención es negociar una lista de temas que se volverían a decidir en el Parlamento de Westminster, es decir, negociar la «renacionalización de competencias» ante una UE a la que acusa de déficit democrático y de intrusismo. 


\section{La actualidad institucional de la Unión Europea}

\section{III.1. Consejos europeos y cumbres del euro}

Durante el primer semestre de 2013, y con anterioridad a la cumbre ordinaria de junio, se celebraron tres Consejos Europeos, en febrero, marzo y mayo.

La primera cumbre tuvo lugar los días 7 y 8 de febrero y fue convocada para tratar el Marco Financiero Plurianual 2014-2020, tras el anterior fracaso de la cumbre de noviembre. Tras un Consejo Europeo que se prolongó durante más de 26 horas, los líderes europeos llegaron al acuerdo necesario para planificar los períodos presupuestarios anuales entre 2014 y 2020.

Los líderes de la Unión Europea acordaron un presupuesto reducido de 960.000 millones de euros, lo que significa el primer recorte presupuestario en la historia de la Unión y una notable reducción respecto a la propuesta inicial de la Comisión que ascendía a 1,08 billones de euros.

Herman van Rompuy, presidente del Consejo Europeo, justificó el recorte señalando que el nuevo presupuesto equivaldría a 1\% del PIB de la Unión Europea y afirmó que era «el presupuesto de la moderación», ya que «no podemos ignorar las tremendas dificultades económicas que sufre actualmente Europa».

El acuerdo fue fiel reflejo del forcejeo «clásico» entre Estados miembros y que enfrenta a los que argumentan que el presupuesto comunitario es un lastre para los presupuestos nacionales en épocas económicas difíciles y aquellos que, por el contrario, defienden que la crisis económica hace más necesarios los vínculos cercanos y profundos entre los países.

Quedaba pendiente, en todo caso, la aprobación del acuerdo por parte del Parlamento Europeo. Y el 13 de marzo, el pleno de la Eurocámara rechazaba las grandes cifras planteadas, los casi 960.000 millones de euros en compromisos y los 908.400 millones en pagos para el período 2014-2020.

En palabras del presidente de la Cámara, Martin Schulz, «las cifras adoptadas por el Consejo son las de 2005, las de hace 8 años, y tienen que prorrogarse hasta 2020 . No es difícil entender que en 2020 nadie podrá respetar los compromisos con la cantidad que tenían en 2005».

El desacuerdo daba pie al inicio de una nueva negociación de los presupuestos 2014-2020 entre el Parlamento, el Consejo y la Comisión.

El 14 y 15 de marzo volvieron a reunirse los líderes europeos de la Eurozona y de toda la UE en sendas cumbres. En esta ocasión, los dirigentes comunitarios estudiaron nuevas medidas para reactivar el crecimiento económico, generar empleo y ayudar a los jóvenes en paro. 
Previamente a la reunión, los países del sur, y en especial Francia, Italia y España trataron de formar una alianza para liderar la idea de acompañar los ajustes con políticas de estímulo. La propia Comisión parecía haber iniciado un cierto cambio de dirección al valorar la posibilidad de flexibilizar los objetivos de Déficit público en determinados países.

Las conclusiones de la cumbre mencionaban la aplicación de una austeridad «diferenciada» por países y de una consolidación fiscal «favorable al crecimiento».

La Comisión propuso a los Veintisiete un programa de «Garantía de Empleo y Formación» para los menores de 25, que les aseguraría una oferta de empleo de calidad, formación continua, aprendizaje o prácticas en un plazo de cuatro meses tras acabar la educación oficial o quedarse en paro. La aprobación por parte de los Estados miembros y del Parlamento Europeo del programa, supondría la movilización de un presupuesto de 6.000 millones de euros durante el periodo 2014-2020.

Los dirigentes de la UE también estudiaron medidas para que los jóvenes adquieran las competencias que la Economía necesita. El sector de la tecnología digital, por ejemplo, tiene problemas para cubrir puestos vacantes y de aquí a 2015 necesitará 900.000 trabajadores más. Para solucionarlo, la Comisión ha creado «un programa de competencias» para coordinar las actividades de las empresas, asociaciones y países de la UE destinadas a suplir estas carencias.

Finalmente, se celebró un Consejo Europeo el 22 de mayo. En esta nueva reunión, los líderes europeos debatieron sobre el intercambio de datos bancarios y sobre la vigilancia de las grandes corporaciones que recurren a la ingeniería financiera.

Austria y Luxemburgo, únicos países de la Unión con el secreto bancario en vigor, se comprometieron a colaborar con sus socios para que las grandes fortunas no esquiven el pago de impuestos. La condición que ambos países plantearon para acometer este cambio es que también Suiza adoptase medidas similares, para evitar que los ahorradores desplacen sus depósitos al país helvético. De hecho, la UE ha iniciado negociaciones con Berna con el objetivo de poder cerrar un acuerdo antes de fin de 2013, lo que significaría un gran avance en la lucha contra el fraude ya que posibilitaría un intercambio fluido de información.

Los Veintisiete también aprobaron el reforzamiento del cerco fiscal a las grandes corporaciones para que no saquen partido de los resquicios legales. El acuerdo alcanzado permitirá combatir las «ingenierías contables» de empresas que, como Google, Amazon o Apple, llevan a cabo «planificaciones fiscales agresivas» que les permiten una escandalosa minimización en el pago de sus impuestos mediante el traslado ficticio de beneficios a las jurisdicciones de la UE con menor presión fiscal. 
Según los datos manejados por la Comisión, las arcas públicas dejan de recaudar un billón de euros al año. Sólo en España se pierden unos 72.000 millones anuales, lo que equivale al 7\% del PIB.

Entre los compromisos alcanzados en esta materia destaca el «intercambio de información automático y universal» entre las Haciendas públicas, compromiso que deberá contemplarse en un nuevo proyecto de Directiva comunitaria sobre cooperación administrativa.

El Consejo Europeo también encargó a la Comisión un informe para analizar los factores que provocan los elevados precios y costes de la energía. Los Veintisiete pidieron que se incidiera en diferentes aspectos, como la adopción de los códigos de red pendientes, la aplicación de la Directiva de fomento de las renovables y del Reglamento relativo a la seguridad de suministro de gas, la aceleración del despliegue de redes y contadores inteligentes así como la facilitación del cambio de proveedor y la defensa de los consumidores vulnerables.

\section{III.2. Eurogrupo: relevo en la presidencia}

El 10 de enero, Jean-Claude Juncker se despedía de su cargo de presidente del Eurogrupo, cargo que había ocupado desde 2005.

En una intervención ante el Parlamento Europeo, Juncker, quien además de ministro de Finanzas es Primer ministro de Luxemburgo desde 1995, admitía tener «muchas dudas» sobre el ritmo de los ajustes impuestos a los socios periféricos. En un discurso que muchos analistas interpretaron como una dura crítica al «dictado» alemán, el luxemburgués señaló que «algunos gobiernos subestiman la enorme tragedia del paro» y recomendó a su sucesor que escuchara a los países del sur para evitar que «la moneda única se encamine al desastre».

$\mathrm{Su}$ sucesor, el ministro de Finanzas holandés Jeroen Dijsselbloem, de 46 años, fue nombrado presidente del Eurogrupo unos días después, el 21 de enero, con la única oposición de España, que hacía público así su malestar por considerarse infra-representada en las instituciones del Euro tras perder un puesto en el Comité Ejecutivo del Banco Central Europeo.

La candidatura del holandés fue posible gracias al consenso por pertenecer al partido laborista, lo que facilitó el respaldo de Francia, y por proceder de un país que defiende las políticas de austeridad que enarbola Berlín. Sus críticos, sin embargo, le recriminaban tanto su corta experiencia en la cartera de finanzas holandesa, con sólo 100 días en el ministerio, como su escasa experiencia en la Unión Europea; por su parte, sus defensores apuntaban sus capacidades diplomáticas. 


\section{Cuestiones generales de la actualidad económica}

\section{IV.1. BCE: nueva rebaja de los tipos de interés}

El Consejo de gobierno del Banco Central Europeo decidió el 2 de mayo reducir los tipos de interés un cuarto de punto, situándolos en el 0,5\%, un nuevo mínimo histórico desde el nacimiento del euro en 1999.

La decisión, según los expertos, era obligada dados los más que preocupantes signos de estancamiento en la Economía europea, con cinco trimestres consecutivos de caídas del PIB y con casi 20 millones de desempleados, y considerando que la inflación se situaba en niveles mínimos, un 1,2\% en marzo.

Muchos analistas señalaron, sin embargo, que la rebaja de tipos tendría un impacto limitado sobre la Economía real al estar ya tan cerca del 0\%, y es por ello que cada vez son más las opiniones que acusan al BCE de ocuparse sólo de las entidades financieras y de no estar «a la altura» de los demás grandes Bancos Centrales del mundo, mucho más activos a la hora de apoyar el crecimiento.

El presidente del Consejo Europeo, Herman Van Rompuy, también mostró su claro malestar por esta inacción, y reclamó al $\mathrm{BCE}$ «un mayor compromiso» para combatir la fragmentación del mercado financiero europeo que obliga a las pymes españolas e italianas, por ejemplo, a pagar intereses del $6 \%$ por sus créditos, mientras que las austríacas o belgas pagan el $2 \%$. El líder comunitario llamó la atención sobre el «enorme lastre» que las restricciones del crédito suponen para la recuperación.

En la tradicional rueda de prensa posterior a la reunión del BCE, su presidente, Mario Draghi, también se mostró preocupado por las dificultades de acceso de las pymes al crédito y reconoció que el grupo de trabajo de la institución que está analizando posibles soluciones desde hace medio año se encuentra aún en una fase de estudio incipiente. Muchas opiniones expertas señalan que las medidas extraordinarias del BCE que desatasquen el crédito y consigan un mayor impacto de las rebajas de tipos en todos los países de la Eurozona, deberán esperar a las elecciones alemanas de Septiembre.

\section{IV.2. Gobernanza económica: paquete legislativo sobre supervisión presupuestaria («two pack»)}

La Comisión Europea, el Parlamento Europeo y el Consejo de la UE alcanzaron el 20 de Febrero un acuerdo definitivo sobre la legislación conocida como «Two-Pack», es decir, sobre los dos Reglamentos comunitarios 
que pretenden reforzar el poder de las autoridades europeas sobre el control de las cuentas de los países de la Eurozona.

Según estas normas, los Estados deberán enviar a la Comisión los presupuestos nacionales antes de su aprobación por los Parlamentos de cada país. Si Bruselas detectara un «incumplimiento serio» del Pacto de Estabilidad y Crecimiento (Déficit público superior al 3\% del PIB y Deuda superior al 60\%), podría requerirse una propuesta revisada. Y si el Estado incumpliera este requerimiento, la Comisión podría notificar esta circunstancia al Eurogrupo, quien podría debatirlo.

A pesar de que la soberanía presupuestaria permanece en los Parlamentos estatales, la nueva normativa significa que tanto la Comisión como el Eurogrupo podrán ejercer una mayor presión política sobre los gobiernos más «indisciplinados».

Además, los países que, según la Comisión, atraviesen dificultades financieras o se vean amenazados por ellas, se verán sometidos a una «vigilancia reforzada», similar a la establecida para los países que han sido rescatados, con misiones periódicas al país e informes de conclusiones de la Comisión. Y también se establece que la Comisión tendrá la potestad de recomendar a un país que solicite un rescate al Mecanismo Europeo de Estabilidad (MEDE), con el fin de evitar retrasos que empeoren la situación.

Por otra parte, el acuerdo también prevé la creación de un grupo de expertos para «profundizar en el análisis de los posibles beneficios, riesgos, requisitos y obstáculos para una sustitución parcial de la emisión de Deuda por parte de los países por una emisión conjunta», lo que permitiría rebajar la presión sobre los países más atacados por los mercados gracias a una «mutualización parcial de la Deuda pública». El comité deberá emitir un informe antes de marzo de 2014 y si la Comisión lo considera oportuno, elaborará una propuesta antes del verano del año próximo.

El paquete legislativo sobre supervisión presupuestaria entró en vigor el 30 de mayo y afectará, por vez primera, a la elaboración de los planes presupuestarios de 2014 de los Estados de la Eurozona. Éstos deberán haber enviado sus proyectos de presupuesto antes del 15 de octubre a la Comisión, y el veredicto de Bruselas, teniendo en cuenta las recomendaciones emitidas en primavera para cada país, llegará el 30 de noviembre.

\section{IV.3. Tribunal de Justicia: Sentencia sobre la ley hipotecaria española}

El Tribunal de Justicia de la UE hizo pública el 14 de marzo una sentencia sobre una pregunta remitida por un juez mercantil de Barcelona, en la que le interrogaba sobre la conformidad de la ley hipotecaria española con la legislación europea de protección de los consumidores. 
En efecto, la Corte europea opinaba que la norma entra en contradicción con una Directiva de 1993 sobre cláusulas abusivas en los contratos celebrados con los consumidores, al no permitir a los jueces españoles adoptar medidas cautelares, como es la paralización de un desahucio.

La normativa hipotecaria española establece que si la persona hipotecada deja de pagar algún mes a la entidad bancaria, ésta podría desahuciarla a través de un procedimiento acelerado. Si el deudor considera que el contrato que firmó contiene cláusulas abusivas, puede acogerse a un procedimiento más largo, denominado declarativo, cuya resolución se dilata en el tiempo, siendo muy posible que la hipoteca se ejecute antes del fallo judicial, de manera que si, incluso el fallo fuera favorable al deudor, éste podría reclamar una indemnización pero ya habría perdido su casa.

Según el Tribunal de Luxemburgo, estas disposiciones vulneran la Directiva comunitaria de protección de los consumidores, ya que según lo señalado en su sentencia el juez que conozca el proceso declarativo debería poder adoptar medidas cautelares, como la suspensión de la ejecución del desalojo, «para garantizar la plena eficacia de su decisión final».

Se trata, por tanto, de que los ciudadanos con hipotecas puedan paralizar un procedimiento de expulsión de su vivienda si consideran que la hipoteca contenía cláusulas abusivas. Dicho de otro modo, se trataría de proteger a los consumidores contra posibles abusos en las hipotecas y evitar que pierdan su vivienda antes de poder demandar a la entidad financiera que les concedió el préstamo por malas prácticas.

Los medios de comunicación se hicieron amplio eco de la repercusión de la sentencia comunitaria, ya que a partir de su publicación deberá aplicarse en todos los casos de ejecuciones hipotecarias que se tramiten en nuestro país, y porque el gobierno español se veía obligado a adaptar el proyecto de ley hipotecaria en marcha para evitar la incompatibilidad detectada por el Alto Tribunal.

\section{IV.4. Política de competencia: nueva multa a Microsoft}

En marzo la Comisión Europea impuso a Microsoft una nueva multa multimillonaria de 561 millones de euros, por no cumplir con sus compromisos de permitir a los usuarios elegir fácilmente un navegador en una versión de Windows 7.

Bruselas señalaba que el gigante estadounidense había incumplido el acuerdo alcanzado en 2009 con las instituciones europeas por el que se comprometía a ofrecer en su sistema operativo una pantalla para elegir un navegador de internet distinto a su Explorer hasta 2014. En concreto, Mi- 
crosoft no cumplió con esa obligación en su versión Service Pack 1 de Windows 7 entre mayo de 2011 y julio de 2012, lo que, según Bruselas, dejó sin elección clara de navegador a 15 millones de usuarios.

Según explicaron fuentes de la Comisión, el compromiso era legalmente vinculante, ya que con él el Ejecutivo comunitario había aceptado cerrar su investigación sobre los problemas de competencia que suponía la venta de Internet Explorer junto a su sistema operativo Windows, que domina el mercado de los ordenadores personales. Y de hecho, se trataba de la primera decisión de la Comisión que sanciona a una empresa por no cumplir con compromisos legalmente vinculantes acordados en el ámbito de las investigaciones sobre la libre competencia.

Según Bruselas, para establecer la cuantía de la multa se tuvo en cuenta «la gravedad y la duración de la infracción, la necesidad de garantizar un efecto disuasorio con la sanción y, como circunstancia atenuante, el hecho de que Microsoft ha cooperado con la Comisión». Efectivamente, la empresa estadounidense había reconocido su incumplimiento, achacándolo a un error técnico que luego remedió. Microsoft se enfrentaba a una posible multa de hasta un $10 \%$ de su facturación total anual, lo que hubiera significado más de 4.000 millones de euros.

Microsoft ya había sido multada anteriormente por el Ejecutivo comunitario. En febrero de 2008, la Comisión decidió imponerle una sanción de 899 millones de euros al considerar que, de junio de 2006 a octubre de 2007, las tarifas de remuneración que proponía para dar acceso a la información relativa a la interoperabilidad no eran razonables. En junio de 2012, el Tribunal de la UE respaldó «en esencia» esta decisión de la Comisión de 2008, aunque redujo ligeramente el importe de la multa a 860 millones de euros.

Previamente, Bruselas ya había impuesto a la compañía otras dos multas de 497 millones de euros en 2004 y de 280,5 millones en 2006, por negarse a facilitar a sus competidores datos de interoperabilidad y a autorizar su uso para el desarrollo y la distribución de productos que compitieran con los suyos en el mercado de los sistemas operativos para servidores de grupos de trabajo.

\section{IV.5. Banca: nueva norma sobre la remuneración de los directivos y avances en la unión bancaria}

El Parlamento Europeo aprobó el 16 de abril una normativa que impondrá límites a la remuneración variable de los directivos bancarios y una mayor exigencia de capital de mayor calidad a la banca, con el objetivo último de blindar al sector ante futuras crisis. 
Según el texto de la nueva Directiva, las primas que cobran los ejecutivos de la banca europea no podrán superar su sueldo fijo anual. Únicamente si los accionistas del banco lo autorizan, el bonus podría alcanzar el máximo del doble del salario (con lo que la remuneración que percibiría el directivo alcanzaría, como máximo, el triple de su salario fijo). Esta autorización exigirá una votación con un quórum en el que esté representado el $50 \%$ del capital social de la empresa y que cuente con el apoyo del $66 \%$ de los accionistas. Si el quórum de votos emitidos no alcanza el 50\%, la propuesta también podría ser aprobada con apoyo del $75 \%$ de los accionistas presentes en el sufragio.

Por otra parte, la exigencia de un mayor porcentaje de capital de máxima calidad pretende evitar que se repita lo sucedido durante la crisis financiera, cuando los bancos no han contado con suficiente capital de calidad para hacer frente al profundo deterioro de sus activos lo que ha provocado que muchos de ellos hayan debido ser rescatados con dinero público. Con la nueva norma, se espera asegurar que las entidades sean capaces de hacer frente a las peticiones de devolución de depósitos y al pago de deudas a acreedores en un contexto de crisis financiera como el que ha llevado al rescate de un gran número de bancos en la zona del euro.

Asimismo, la Directiva obligará a los bancos a nuevas prácticas de transparencia. Les exigirá que desvelen sus beneficios, los impuestos pagados y las subvenciones recibidas de forma desagregada país por país, así como el volumen de negocios y el número de trabajadores. Desde 2014, estos datos deberán enviarse a la Comisión, y a partir de 2015 tendrán que publicarse.

La norma establece duras sanciones contra las entidades y los ejecutivos de banca que la incumplan. Entre ellas figura «la declaración pública que indique la persona física o jurídica y la naturaleza de la infracción».

Si el infractor es un banco como persona jurídica se prevé «la revocación de la autorización de la entidad», así como «sanciones pecuniarias administrativas de hasta el $10 \%$ de su volumen de negocios total en el ejercicio anterior».

En el caso de las personas físicas, se prevé la imposición de «una prohibición temporal de ejercer funciones en entidades a alguno de los miembros del órgano de dirección de la entidad, o a cualquier otra persona física que se considere responsable» y también la imposición de multas de hasta cinco millones de euros.

El proyecto normativo había sido acordado entre la Eurocámara y la Comisión Europea a finales de febrero, después de una larga negociación en la que Londres había tratado de evitar que se impusiera un máximo en las retribuciones extraordinarias de los directivos de banca. Los ministros de Economía y Finanzas, sin embargo, ratificaron ese pacto a principios de marzo. 
La norma, que es la «traducción» al Derecho comunitario del conjunto de normas internacionales sobre capital bancario, conocidas como «Basilea III», entrará en vigor el 1 de enero de 2014.

«Por primera vez en la historia de la regulación financiera de la UE, vamos a poner topes a los bonus de los banqueros», dijo el representante de la Eurocámara, Othmar Karas. «El objetivo, más allá de las cuestiones de moral, es limitar los bonus que se pagaban de manera injustificable e injustificada», señaló el comisario de Mercado Interior, Michel Barnier.

La norma dejaba en minoría al Reino Unido, que se había opuesto a cualquier tope alegando que lo único que se logrará es que aumente la parte fija de los salarios de los banqueros. En la posición británica subyace el hecho de que en la City londinense estos recortes podrían suponer una complicación en las estructuras de remuneración de las entidades financieras y que podría afectar a alrededor de 144.000 empleados del sector. Los británicos también alertaban de una eventual fuga de directivos europeos hacia otras plazas internacionales.

Por otra parte, los ministros de Economía y Finanzas de la Eurozona, lograron un acuerdo político el 20 de junio que limita a 60.000 millones de euros el uso del Mecanismo de Estabilidad, MEDE, para la recapitalización directa de la banca. La posibilidad de aplicarla con carácter retroactivo (en los casos de Irlanda, Grecia o España), circunstancia que evitaría el cómputo de los rescates como Deuda pública, se examinará «caso por caso», según señaló el presidente del Eurogrupo, Jeroem Dijsselbroem.

El acuerdo significará, según muchos analistas, un importante paso hacia la Unión Bancaria, y también un factor de reducción del riesgo de contagio del sector financiero al sector púbico.

Los países sólo podrán pedir la recapitalización directa de una entidad como último recurso, es decir, cuando las quitas a accionistas y acreedores (salvo a los depósitos inferiores a 100.000 euros) no sean suficientes para cubrir el déficit de capital y el gobierno nacional no pueda inyectar fondos sin poner en riesgo su estabilidad presupuestaria. La entidad deberá tener carácter sistémico y su quiebra plantear un riesgo para la estabilidad de la Eurozona.

Antes de cualquier decisión, el MEDE, la Comisión y el Banco Central Europeo examinarán si la entidad es viable y la someterán a un test de estrés para verificar el capital necesario. Si la entidad no alcanzara el ratio mínimo legal de capital, el Estado beneficiario deberá aportar el capital necesario para llegar a este nivel antes de que el MEDE intervenga. Si ya lo cumple, el país receptor deberá contribuir con el 20\% de los costes del rescate durante los dos primeros años y con el $10 \%$ después, mientras que el MEDE será quien asuma el resto. 
En cambio, al día siguiente, 21 de junio, los ministros de Finanzas del conjunto de la Unión Europea no lograron ponerse de acuerdo sobre la futura Directiva de reestructuración y resolución bancaria de la UE, una norma que pretende, en definitiva, que sean los accionistas y los acreedores los que paguen la factura en casos de quiebras bancarias, y no los contribuyentes.

El ministro español de Economía y Competitividad, Luis de Guindos, señaló a la salida de la reunión que «los depósitos de menos de 100.000 euros están absolutamente cubiertos, así como los depósitos de más de 100.000 en manos de pymes y personas físicas».

Según el ministro, el Ecofin se atascó en la definición del porcentaje de pasivos de los bancos que pueden sufrir pérdidas y en el de los que pueden ser eximidos o parcialmente excluidos en circunstancias excepcionales y bajo estrictas condiciones.

La Presidencia irlandesa propuso vincular esa flexibilidad al tamaño de los bancos en dificultades y al tamaño de los Fondos nacionales de resolución que se crearán en los Estados miembros. Estos fondos nacionales pueden ser nuevos o juntarse con los fondos de garantías de depósitos, deben ser financiados con aportaciones de las entidades financieras y alcanzar un cierto nivel de cobertura.

La UE estudia también introducir una salvaguardia para evitar una fragmentación del mercado interior. La Comisión Europea tendría que ser informada por las autoridades de resolución nacionales antes de una exclusión de pasivos, e incluso tendría poder de veto si no la ve viable o supera un porcentaje del total de pasivos. 